\title{
Caracterização de derivado arilbutanoídico em folhas e raízes de Ottonia anisum Sprengel
}

\author{
André M. Marques, ${ }^{* 1}$ Leosvaldo S. M. Velozo, ${ }^{1}$ Elsie F. Guimarães, ${ }^{2}$ Maria A. C. Kaplan ${ }^{1}$ \\ ${ }^{1}$ Núcleo de Pesquisas de Produtos Naturais, Universidade Federal do Rio de Janeiro, Avenida Carlos Chagas \\ Filho, 373, Bloco H, Cidade Universitária, 21941-902 Rio de Janeiro-RJ, Brasil, \\ ${ }^{2}$ Instituto de Pesquisa Jardim Botânico do Rio de Janeiro, Unidade de Botânica Sistemática, Rua Pacheco Leão \\ 915, Jardim Botãnico, 22460-030 Rio de Janeiro-RJ, Brasil
}

\begin{abstract}
RESUMO: A família Piperaceae é formada por 5 gêneros, Piper, Peperomia, Pothomorphe, Ottonia e Sarcorhachis, com cerca de 2000 espécies de ampla distribuição nas regiões tropicais e subtropicais do mundo. Das 23 espécies descritas para o gênero Ottonia, a maioria é nativa do Brasil. Essas plantas são popularmente utilizadas no país como diuréticas, salivantes e anestésicas. O estudo químico dos extratos apolares de folhas e de raízes de Ottonia anisum Sprengel levou ao isolamento de um componente majoritário identificado como o derivado arilbutanoídico: 1-butil3,4-metilenodioxibeneno.
\end{abstract}

Unitermos: Piperaceae, Ottonia anisum, 1-butil-3,4-metilenodioxibeneno.

\begin{abstract}
Characterization of an arylbutanoic derivative from leaves and roots of Ottonia anisum Sprengel”. The family Piperaceae encompasses 5 genera, Piper, Peperomia, Pothomorphe, Ottonia and Sarcorhachis, and approximately 2,000 species widely distributed in the tropical and subtropical regions of the world. Most of the Ottonia species are native to Brazil and they are used in folk medicine as diuretic, salivating, and anaesthetic. Chemical studies of non-polar fractions from leaves and roots of Ottonia anisum Sprengel lead to the isolation of an arylbutanoic metabolite, the 1-butyl-3,4-methylenedioxybezene.
\end{abstract}

Keywords: Piperaceae, Ottonia anisum, 1-butyl-3,4-methylenedioxybezene.

\section{INTRODUÇÃO}

A família Piperaceae ocorre de Norte a Sul do Brasil e suas espécies são utilizadas para fins medicinais desde os tempos antigos, sendo por isso uma fonte estimulante para a pesquisa fitoquímica e farmacológica (Nakamura et al., 2006; Amaral et al., 2006; BarbosaFilho et al., 2006a,b; Potzernheim et al., 2006; Amorim et al., 2007; Barbosa-Filho et al., 2008; Sousa et al., 2008). Essa família pertence à superordem Nymphaeiflorae, ordem Piperales e é formada por 5 gêneros, Piper, Peperomia, Pothomorphe, Ottonia e Sarcorhachis, com cerca de 2000 espécies de ampla distribuição nas regiões tropicais e subtropicais do mundo (Dahlgren, 1980). Das 23 espécies descritas para o gênero Ottonia, a maioria é nativa do Brasil, sendo encontradas, principalmente, nas regiões Sul e Sudeste (Yuncker, 1973). Essas plantas são popularmente utilizadas no país como diuréticas, salivantes e anestésicas, sendo muitas vezes conhecidas como "anestesia" e "falso jaborandi" (Lopes, 1989; Cunico, 2001; Cunico et al., 2004; Agra et al., 2007 and 2008). A espécie Ottonia anisum é uma fonte promissora de metabolitos secundários dentre os quais as amidas são de grande interesse medicinal (Antunes et al., 2001).
Nesse intuito alguns pesquisadores vêm buscando explorar as potencialidades dessa planta. O isolamento de substâncias a partir do gênero Ottonia teve início com Dustan \& Garnett (1895) os quais trabalharam com Ottonia vahlii quando foi obtido um óleo essencial capaz de provocar o formigamento nos lábios e língua em povos de Trinidad, onde a mesma era utilizada para fins medicinais. Pinder \& Price (1967) elucidaram a estrutura molecular dessa substância como $\mathrm{C}_{11} \mathrm{H}_{14} \mathrm{O}_{2}$, denominando-a de 1-butil-3,4-metilenodioxibeneno. Giesbrecht et al. (1981), chegaram a mesma substância a partir de raízes e caules de Ottonia anisum. Moreira et al. (1997), identificaram a presença de 1-butil3,4-metilenodioxibeneno como sendo o componente majoritário (95\%) do óleo essencial de folhas de $O$. anisum. Contudo o mesmo produto não foi encontrado por Santos et al., (2001). Apesar de já ser utilizada na medicina popular em algumas regiões do país, pouco se sabe sobre a riqueza e o potencial químico e biológico dessa espécie.

\section{MATERIAL E MÉTODOS}

Coleta e identificação do material vegetal 
Partes aéreas e raízes de Ottonia anisum foram coletadas em março de 2007 no município de Xerém, Estado do Rio de Janeiro, RJ. O material botânico foi identificado pela botânica Dra. Elsie Franklin Guimarães e detém exsicata depositada no Herbarium RB do Instituto de Pesquisas Jardim Botânico do Rio de Janeiro, sob o número RB393494. Após a coleta o material vegetal foi separado nos seus diferentes órgãos: folhas e raízes, que foram reduzidos a pequenos fragmentos utilizando tesoura de poda e, em seguida, submetidos à extrações com solventes orgânicos.

O isolamento e a purificação de substâncias químicas por cromatografia de adsorção em coluna, foram feitos utilizando como adsorvente gel de sílica $60(0,063$ - 0,200 mm e 0,040 - 0,063 mm; Merck). As frações foram reunidas com base na análise comparativa por cromatografia de adsorção em camada delgada sobre gel de sílica. O critério de pureza utilizado foi a presença de uma única mancha em placa cromatográfica analítica, sinal único na análise por cromatografia em fase gasosa. Para determinação estrutural das substâncias químicas isoladas e em misturas utilizou-se cromatografia em fase gasosa acoplada à espectrometria de massas em aparelho GC MS QP5000 Shimadzu, a 70eV provido de uma coluna ZB-5MS ( $30 \mathrm{~m} \times 0,25 \mathrm{~mm} \times 0,25 \mu \mathrm{m})$, injetor a $260{ }^{\circ} \mathrm{C}$, interface a $200{ }^{\circ} \mathrm{C}$, operando com variação de temperatura de $60{ }^{\circ} \mathrm{C}$ a $290{ }^{\circ} \mathrm{C}\left(10^{\circ} \mathrm{C} / \mathrm{min}\right)$ sendo hélio o gás de arraste $(1 \mathrm{ml} / \mathrm{min})$. Os espectros de $\mathrm{RMN}{ }^{1} \mathrm{H}$ e ${ }^{13} \mathrm{C}$ foram realizados em espectrômetro Brüker modelo DRX com os campos de 400,13 $\mathrm{MH}_{\mathrm{z}}$ para hidrogênio e 100,61 MHz para carbono. Todos os solventes utilizados na solubilização das substâncias eram deuterados e TMS foi usado como padrão interno. Comparação com padrão foi utilizada para confirmação do produto isolado.

\section{Obtenção dos extratos}

O material fresco e fragmentado foi extraído por maceração estática, sucessivamente, com hexano por três dias, com troca diária de solvente e com metanol por cinco dias, com troca diária de solvente. O extrato metanólico suspenso em $\mathrm{MeOH} / \mathrm{H}_{2} \mathrm{O}$ (3:7) foi submetido às partições líquido-líquido em seqüência com hexano, diclorometano, acetato de etila e butanol. Os extratos brutos hexânico e metanólico e as frações resultantes das partições do extrato metanólico com os solventes descritos foram fracionados por metodologia cromatográfica para obtenção de substâncias puras.

Fracionamento do extrato hexânico de raízes de $O$. anisum

O extrato hexânico de $O$. anisum foi fracionado em coluna cromatográfica de gel de sílica eluída com sistemas de solventes preparados com misturas binárias de hexano, acetato de etila e metanol em gradiente de polaridades crescentes, além dos solventes puros, resultando em 80 frações. As frações 4 e 5 (0,68 g), eluídas da coluna com hex/AcOEt 2\% e apresentando um aspecto oleoso, foram reunidas e analisadas por cromatografia em fase gasosa resultando na identificação do derivado arilbutanoídico, 1-butil-3,4metilenodioxibenzeno (1).

Fracionamento do extrato metanólico de folhas de $O$. anisum

O extrato metanólico $(43,50$ g) foi submetido à partição líquido-líquido com diferentes solventes fornecendo as seguintes frações: fração hexânica, fração diclorometânica, fração em acetato de etila e fração butanólica.

\section{Fração hexânica}

A fração hexânica (11,75 g) foi submetida à cromatografia em coluna filtrante sobre gel de sílica utilizando como eluentes, hexano; diclorometano; acetato de etila; e metanol resultando em 4 frações. A fração 1, eluída da coluna com hexano puro, foi submetida à cromatografia sobre gel de sílica e eluída com sistemas de solventes preparados com misturas binárias de hexano, acetato de etila e metanol em gradiente de polaridades crescentes, resultando em 103 frações. De acordo com a semelhança cromatográfica juntaram-se as frações 4-7 obtendo um óleo (1,18 g) com odor característico. Esse material foi analisado por cromatografia com fase gasosa, resultando na identificação de um derivado arilbutanoídico: 1-butil-3,4-metilenodioxibezeno (1). A fração 4-7, eluída da coluna com Hex/AcOEt 2\%, foi codificada como OA-4 analisada por RMN de ${ }^{1} \mathrm{H}$ e ${ }^{13} \mathrm{C}$, COSY, APT, resultando na caracterização da substância 1-butil-3,4-dioximetilbenzeno (1).

RMN ${ }^{1} \mathrm{H}\left(400,13 \mathrm{MHz}, \mathrm{CDCl}_{3}\right): \delta 0,95$ (3H, t, J=7,4 Hz, H-4'), 1,30 (2H, m, H-3'), 1,55 (2H, m, H-2'), $2,50\left(2 \mathrm{H}, \mathrm{t}, \mathrm{J}=7,4 \mathrm{~Hz}, \mathrm{H}-1^{\prime}\right), 5,90\left(2 \mathrm{H}, \mathrm{s}, \mathrm{O}-\mathrm{CH}_{2} \mathrm{O}\right)$, 6,62 (1H, dd, J=7,70 Hz e 0,85 Hz), H-6) 6,68 (1H, d, $\mathrm{J}=0,85 \mathrm{~Hz}, \mathrm{H}-2), 6,79(1 \mathrm{H}, \mathrm{d}, \mathrm{J}=7,70 \mathrm{~Hz}, \mathrm{H}-5)$. RMN ${ }^{13} \mathrm{C}$ (100,61 MHz): $\delta$ 136,61 (C-1), 108,70 (C-2), 147,30 (C-3), 145,24 (C-4), 107,84 (C-5), 120,86 (C-6), 35,23 (C-1'), 33,77 (C-2'), 22,08 (C-3’), 13,79 (C-4'), 100,52 $\left(\mathrm{O}-\mathrm{CH}_{2}-\mathrm{O}\right)$.

\section{RESULTADOS E DISCUSSÃO}

Fracionamento do extrato hexânico de folhas de Ottonia anisum, por cromatografia em coluna eluída com Hexano/AcOEt 2\%, forneceu um produto puro codificado como OA-04. Análise dos dados espectrais permitiu propor para a substância OA-04 a estrutura 1-butil-3,4-metilenodioxibenzeno (1) (Figura 1).

Espectros de RMN ${ }^{1} \mathrm{H}$ e COSY mostraram sinais em $\delta 0,93\left(3 \mathrm{H}, \mathrm{t}, \mathrm{J}=7,0 \mathrm{~Hz}, \mathrm{H}-4^{\prime}\right) ; \delta 1,34(2 \mathrm{H}$, $\left.\mathrm{m}, \mathrm{H}-3^{\prime}\right) ; \delta 2,56\left(2 \mathrm{H}, \mathrm{m}, \mathrm{H}-2^{\prime}\right) ; \delta 2,53(2 \mathrm{H}, \mathrm{t}, \mathrm{J}=7,0$, 


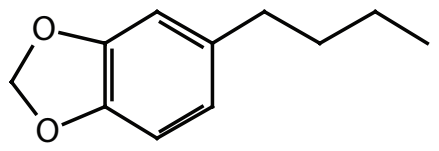

Figura1.Estruturaquímicado1-butil-3,4-metilenodioxibenzeno (1).

H-1'); $\delta 5,9$ (2H, s) esse último atribuído aos $\mathrm{H}$ do grupo metilenodioxílico $\mathrm{OCH}_{2} \mathrm{O}$, além de um sinal multipleto em $\delta 6,55-6,75(3 \mathrm{H}, \mathrm{m})$ que foi alocado para os átomos de hidrogênio do anel aromático (H-2, H-5 e H-6). O espectro de RMN ${ }^{13} \mathrm{C}$ juntamente com os das técnicas APT e HETCOR, além de comparação com dados da literatura segundo Moreira et al (1997) mostraram-se essenciais para referendar a estrutura proposta (Tabela 1).

Tabela 1. Dados de deslocamento químico exibidos por AO-04 nos espectros de $\mathrm{RMN}{ }^{1} \mathrm{H}$ e $\mathrm{RMN}{ }^{13} \mathrm{C}$.

\begin{tabular}{ccc}
\hline $\mathrm{C}$ & ${ }^{1} \mathrm{H}$ & $\mathrm{C}$ \\
\hline 1 & - & 136,7 \\
2 & $6,55-6,75(\mathrm{~m})$ & 120,9 \\
3 & - & 147,3 \\
4 & - & 145,2 \\
5 & $6,55-6,75(\mathrm{~m})$ & 108,7 \\
6 & $6,55-6,75(\mathrm{~m})$ & 107,9 \\
1 & $2,53(2 \mathrm{H}, \mathrm{t}, \mathrm{J}=7,0 \mathrm{~Hz})$ & 35,26 \\
2 & $1,56(2 \mathrm{H}, \mathrm{m})$ & 33,80 \\
$3^{\prime}$ & $1,34(2 \mathrm{H}, \mathrm{m})$ & 22,11 \\
4 & $0,93(3 \mathrm{H}, \mathrm{t}, \mathrm{J}=7,0 \mathrm{~Hz})$ & 13,83 \\
$\mathrm{O}-\mathrm{CH}{ }_{2}-\mathrm{O}$ & $5,90(2 \mathrm{H}, \mathrm{s})$ & 100,5 \\
\hline
\end{tabular}

A identificação da estrutura molecular de (1) também foi mediada por co-injeção com padrão. Em ambos os órgãos (folhas e raízes), o rendimento do produto puro obtido: 1-butil-3,4-metilenodioxibenzeno (1) foi semelhante, sendo $0,122 \%$ para raiz e $0,117 \%$ para folhas. Com esse rendimento foi possível isolar cerca de 1,85g dessa substância. Esse material encontrase no Banco de Extratos do nosso acervo, aguardando avaliação de suas potencialidades terapêuticas a confirmar o uso da planta na medicina tradicional.

\section{CONCLUSÃO}

O estudo químico das frações apolares de folhas e de raízes de Ottonia anisum Sprengel levou ao isolamento de um derivado arilbutanoídico, 1-butil-3,4metilenodioxibenzeno (1), em frações apolares, como o componente majoritário.

\section{AGRADECIMENTOS}

À CAPES E CNPq pelas bolsas recebidas.

\section{REFERÊNCIAS}

Agra MF, França PF, Barbosa-Filho JM 2007. Synopsis of the plants known as medicinal and poisonous in Northeast of Brazil. Rev Bras Farmacogn 17: 114140.

Agra MF, Silva KN, Basílio IJLD, França PF, Barbosa-Filho JM 2008. Survey of medicinal plants used in the region Northeast of Brazil. Rev Bras Farmacogn 18: 472-508.

Amaral FMM, Ribeiro MNS, Barbosa-Filho JM, Reis AS, Nascimento FRF, Macedo RO 2006. Plants and chemical constituents with giardicidal activity. Rev Bras Farmacogn 16 (Supl.): 696-720.

Amorim MFD, Diniz MFFM, Araújo MST, Pita JCLR, Dantas JG, Ramalho JA, Xavier AL, Palomaro TV, Júnior NLB 2007. The controvertible role of kava (Piper methysticum G. Foster) an anxiolytic herb, on toxic hepatitis. Rev Bras Farmacogn 17: 448-454.

Barbosa-Filho JM, Medeiros KCP, Diniz MFFM, Batista LM, Athayde-Filho PF, Silva MS, Cunha EVL, Almeida JRGS, Quintans-Júnior LJ 2006a. Natural products inhibitors of the enzyme acetylcholinesterase. Rev Bras Farmacogn 16: 258-285.

Barbosa-Filho JM, Martins VKM, Rabelo LA, Moura MD, Silva MS, Cunha EVL, Souza MFV, Almeida RN, Medeiros IA 2006b. Natural products inhibitors of the angiotensin converting enzyme (ACE). A review between 1980-2000. Rev Bras Farmacogn 16: 421446.

Barbosa-Filho JM, Alencar AA, Nunes XP, Tomaz ACA, Sena-Filho JG, Athayde-Filho PF, Silva MS, Souza MFV, da-Cunha EVL 2008. Sources of alpha-, beta-, gamma-, delta- and epsilon-carotenes: A twentieth century review. Rev Bras Farmacogn 18: 135-154.

Antunes PA, Chierice GO, Constantino RF 2001. Spectroscopic characterization of $\mathrm{N}$-isobutyl-6-( $p$-metoxyphenyl) 2E, 4E-hexadieneamide extracted from Ottonia propinqua. Vib Spectrosc 27: 175-181.

Cunico MM 2001. Estudo fitoquímico e das atividades antimicrobianas da Ottonia martiana Miq. Piperaceae. Curitiba, 83p. Dissertação de Mestrado em Ciências Farmacêuticas - Setor de Ciências da Saúde, Universidade Federal do Paraná.

Cunico MM, Carvalho JLS, Kerber VA, Higaskino CEK, Cruz-Almeida SC, Miguel MD, Miguel OG 2004. Atividade antimicrobiana do extrato bruto etanólico de raízes e partes aéreas de Ottonia martiana Miq. (Piperaceae). Rev Bras Farmacogn 14: 97-103.

Dahlgren RMT 1980. A revised system of classification of the angiosperms. Bot J Linn Soc 80: 91-124.

Dunstan WR, Garnett H 1895. The constituents of Piper ovatum. J Chem Soc 67: 94-100.

Giesbrecht AM, Alvarenga MA, Gottlieb OR, Gottlieb HR 1981. (2E,4E)- $N$ - isobutyl-9-piperonyl-nona-2,4 dienoic amide from Ottonia anisum. Planta Med 43: 375.

Lopes M 1989. Contribuição para o estudo fitoquímico de Ottonia martiniana Miq. - Piperaceae. Curitiba, 102p. Dissertação de mestrado em Botânica - Setor de Ciências Biológicas, Universidade Federal do Paraná.

Moreira DL, Kaplan M, Guimarães A 1997. 1-Butil-3,4methylenedioxybenzene as the major constituent essential oil from Ottonia anisum Sprengel 
(Piperaceae). J Essent Oil Res 9: 565-568.

Nakamura CV, Santos AO, Vendrametto MC, Luize OS, Dias Filho BP, Cortez DAG, Ueda-Nakamura T 2006. Atividade antileishmania do extrato hidroalcoólico e de frações obtidas de folhas de Piper regnellii (Miq.) C. DC. var. pallescens (C. DC.) Yunck. Rev Bras Farmacogn 16: 61-66.

Pinder AR, Price SJ 1967. The chemistry of Ottonia vahlii Kth: the volatile constituent. Part I. J Chem Soc C 2598.

Potzernheim MCL, Bizzo HR, Vieira RF 2006. Análise dos óleos essenciais de três espécies de Piper coletadas na região do Distrito Federal (Cerrado) e comparação com óleos de plantas procedentes da região de Paraty, RJ (Mata Atlântica). Rev Bras Farmacogn 16: 246251.

Santos PRD, Moreira DL, Guimarães EF 2001. Essential oil analysis of 10 Piperaceae species from the Brazilian Atlantic Forest. Phytochemistry 58: 547-551.

Sousa PJC, Barros CAL, Rocha JCS, Lira DS, Monteiro GM, Maia JGS 2008. Avaliação toxicológica do óleo essencial de Piper aduncum L. Rev Bras Farmacogn 18: 217-221.

Yuncker TC 1973. The Piperaceae of Brazil. Hoehnea 3: 121138. 